Article

\title{
The Abnormal CD4+T Lymphocyte Subset Distribution and Vbeta Repertoire in New-onset Rheumatoid Arthritis Can Be Modulated by Methotrexate Treament
}

\author{
Jorge Monserrat ${ }^{1,2}$, Cristina Bohórquez ${ }^{2,3}$, Ana María Gómez Lahoz ${ }^{1,3}$, Atusa Movasat ${ }^{2,3}$, \\ Ana Pérez 2,3, Lucía Ruíz 2,3, David Díaz 1,3, Luis Chara 1,3, Ana Isabel Sánchez 2,3, \\ Fernando Albarrán 2,3, Ignacio Sanz ${ }^{4}$ and Melchor Álvarez-Mon 1,2,3,* \\ 1 Laboratory of Immune System Diseases, University of Alcalá, Alcalá de Henares, 28871 Madrid, Spain \\ 2 Department of Medicine, University Hospital "Príncipe de Asturias", University of Alcalá and Instituto \\ Ramón y Cajal de Investigación Sanitaria (IRYCIS), Alcalá de Henares, 28871 Madrid, Spain \\ 3 Immune System Diseases-Rheumatology Service, University Hospital "Príncipe de Asturias", \\ Alcalá de Henares, 28871 Madrid, Spain \\ 4 Division of Immunology and Rheumatology, Department of Medicine, Emory University, Atlanta, \\ GA 30322, USA \\ * Correspondence: mademons@gmail.com; Tel.: +34-1-885-4533; Fax: +34-1-885-4526
}

Received: 15 June 2019; Accepted: 6 August 2019; Published: 10 August 2019

\begin{abstract}
Patients with long-term, treated, rheumatoid arthritis (RA) show abnormalities in their circulating CD4+ T-lymphocytes, but whether this occurs in recently diagnosed naïve patients to disease-modifying drugs (DMARDs) is under discussion. These patients show heterogeneous clinical response to methotrexate (MTX) treatment. We have examined the count of circulating CD4+ T-lymphocytes, and their naïve $\left(\mathrm{T}_{\mathrm{N}}\right)$, central memory $\left(\mathrm{T}_{\mathrm{CM}}\right)$, effector memory $\left(\mathrm{T}_{\mathrm{EM}}\right)$ and effector $\left(\mathrm{T}_{\mathrm{E}}\right)$ subsets, CD28 expression and V $\beta$ TCR repertoire distribution by polychromatic flow cytometry in a population of 68 DMARD-naïve recently diagnosed RA patients, before and after 3 and 6 months of MTX treatment. At pre-treatment baseline, patients showed an expansion of the counts of CD4+ $\mathrm{T}_{\mathrm{N}}, \mathrm{T}_{\mathrm{EM}}, \mathrm{T}_{\mathrm{E}}$ and $\mathrm{T}_{\mathrm{CM}}$ lymphocyte subsets, and of total CD4+CD28- cells and of the $\mathrm{T}_{\mathrm{E}}$ subset with a different pattern of numbers in MTX responder and non-responders. The expansion of CD4+ $\mathrm{T}_{\mathrm{EM}}$ lymphocytes showed a predictive value of MTX non-response. MTX treatment was associated to different modifications in the counts of the CD4+ subsets and of the V $\beta$ TCR repertoire family distribution and in the level of CD28 expression in responders and non-responders. In conclusion, the disturbance of CD4+ lymphocytes is already found in DMARD-naïve RA patients with different patterns of alterations in MTX responders and non-responders.
\end{abstract}

Keywords: rheumatoid arthritis; CD4+ T lymphocytes; methotrexate; flow cytometry; $\mathrm{TCR} \mathrm{Vb}$

\section{Introduction}

Rheumatoid arthritis (RA) is a highly prevalent inflammatory arthritis. It afflicts $1 \%$ of the world's population, reducing both the quality of life and life expectancy [1]. Fortunately, the last decades have seen great advances in the treatment of patients with RA. The possibility of controlling the progression of the disease, including the destruction of the affected joints, has improved through the use of methotrexate (MTX) and biological drugs with anti-tumor necrosis factor alpha (TNF $\alpha$ ) activity $[1,2]$. Novel drugs and biological therapies are also becoming available, but MTX retains a central role in the treatment of RA and remains the most commonly used disease-modifying anti-rheumatic drug 
(DMARD) [3]. However, MTX fails to control disease activity and structural damage in some $30-40 \%$ of patients [4], and the precise mechanism of action of MTX in the treatment of RA remains unclear [5].

It is well established that the cells of the immune system play a pivotal role in the pathogenesis of the joint damage characteristic of RA, as well as in the extra-articular manifestations of the disease [1]. Although the mechanisms regulating this anomalous immune system response are not completely understood, considerable evidence supports that $\mathrm{CD} 4^{+} \mathrm{T}$ cells play a central role in initiating and perpetuating the chronic inflammation characteristic of RA [6-8].

$\mathrm{CD} 4+\mathrm{T}$ lymphocytes are a phenotypically and functionally heterogeneous cell population. Based on their distinctive pattern of activation and effector functions, human $\mathrm{CD} 4^{+} \mathrm{T}$ cells can be divided according to the CCR7, CD27 or CD62L antigen surface expression into different subsets named differently in the literature. The main difference in the expression of these surface antigens is the kinetic of their loss along the different $\mathrm{T}$ activation/differentiation stages $[9,10]$. Therefore, it has been proposed that $\mathrm{CD} 4^{+} \mathrm{T}$ subsets include $\mathrm{CD}^{+} \mathrm{CD}^{+} \mathrm{CD} 45 \mathrm{RA}{ }^{+} \mathrm{CCR} 7^{+}$naïve $\left(\mathrm{T}_{\mathrm{N}}\right)$, $\mathrm{CD}^{+} \mathrm{CD}^{+} \mathrm{CD}^{+} 5 \mathrm{RA}^{-} \mathrm{CCR}^{+}$central memory $\left(\mathrm{T}_{\mathrm{CM}}\right), \mathrm{CD}^{+} \mathrm{CD}^{+}{ }^{+} \mathrm{CD} 45 \mathrm{RA}^{-} \mathrm{CCR} 7^{-}$effector memory $\left(\mathrm{T}_{\mathrm{EM}}\right)$ and $\mathrm{CD}^{+}{ }^{+} \mathrm{CD} 4^{+} \mathrm{CD} 45 \mathrm{RA}^{+} \mathrm{CCR} 7^{-}$effector $\left(\mathrm{T}_{\mathrm{E}}\right)$ subsets [11]. $\mathrm{CD} 4+\mathrm{T}_{\mathrm{N}}$ exhibit non effector function while $\mathrm{CD} 4+\mathrm{T}_{\mathrm{CM}}$ can rapidly proliferate and express multiple different effector molecules such as cytokines after being stimulated by antigen and diminished activation requirements [11-13]. CD4+ $\mathrm{T}_{\mathrm{EM}}$ produce effector cytokines but have limited proliferative capacity and $\mathrm{CD} 4+\mathrm{T}_{\mathrm{E}}$ are at a final differentiation stage and share high levels of cytokine production [14]. The requirements for activation, proliferation and survival of these subsets are different, as well as their capacity to enter in lymphoid and inflamed non-lymphoid tissues [15].

Patients with RA show numerical and functional abnormalities in their CD4+ T lymphocytes both those in the circulation and those at inflamed joints [16-20]. Indeed, the anomalous differentiation of CD4+ naïve into CD4+ memory T lymphocytes, and imbalances between the different CD4+ T lymphocyte subsets, has been described with contradictory results [21-25]. Several factors might be involved in this variability, including the clinical stage of the disease and the previous and active treatments. Further, RA appears to be associated with the accelerated ageing of CD4+ T cells, with the expansion of those that no longer express the CD28 co-stimulatory molecule, and those which show telomere shortening $[17,26]$. The cause of this putative premature immune ageing remains unclear $[27,28]$. The results obtained in patients with long term disease might be secondary to the long-term maintained inflammatory stage of the disease and/or previous and active DMARD or immunosuppressor treatments.

The repertoire of the T cell receptor (TCR) plays a pivotal role in the antigenic self and non-self recognition and activation by CD4+ T lymphocytes [29]. Most of these cells have the alfa-beta type TCR and a given CD4+ T cell displays a single and unique combination of the variable (V), diversity (D) and joining (J) gene regions segments of the variable regions on its cytoplasmic membrane [30]. TCR repertoire represents the genetic background of the individual, in addition to the response to self or environmental antigens, being a very useful approach to understanding the antigen-expansion of $\mathrm{T}$ cells clones [31]. Variations in TCR repertoire have been found in several autoimmune diseases, and may be responsible for the breakdown of peripheral immune tolerance [32]. Heterogeneous results in the TCR repertoire have been described in RA patients [30-43].

To avoid the potential effects of long-term inflammation, DMARDs, other immunomodulatory drugs, and of concomitant disease on CD4+ T lymphocytes, the present work involved a homogenous group of patients recently diagnosed with RA, all of whom were DMARD-naïve. We used as controls a group of sex and age-matched healthy controls. The study of these patients might give information about the alterations of the CD4+ T lymphocytes in RA without the referred potential confusion factors. Furthermore, knowing which DMARD-naïve patients are likely and unlikely to benefit from MTX treatment before it begins would be advantageous for the selection of the treatment. The aim of the present work was therefore to examine the number and distribution of circulating $T_{N}, T_{C M}, T_{E M}$ and $\mathrm{T}_{\mathrm{E}} \mathrm{CD} 4+\mathrm{T}$ lymphocyte subsets, their CD28 expression and their $\mathrm{V} \beta \mathrm{TCR}$ repertoire distribution, 
before and after 3 and 6 months of MTX treatment in a homogenous group of recently diagnosed, DMARD-naïve patients with new-onset RA.

\section{Materials and Methods}

\subsection{Inclusion and Exclusion Criteria}

The study subjects were 68 Caucasian patients, all of whom fulfilled the American College of Rheumatology (ACR)/European League Against Rheumatism (EULAR) 2010 classification criteria for RA [44]. Patients were studied in parallel with 24 healthy sex-, age- and ethnicity-matched (proportionally) controls from areas of similar epidemiological background. The patients were monitored at the Immune System-Rheumatology Service, Hospital Universitario Príncipe de Asturias, Universidad de Alcalá, in Alcalá de Henares, Spain. All gave their informed consent to be included. The study was approved by the hospital's clinical ethics committee.

\subsection{Inclusion Criteria}

Patients with new-onset RA (disease duration $<6$ months), previously untreated with DMARDs were evaluated based on the following entry criteria: age $\geq 18$ years, a diagnosis of RA and less than 3 months since the onset of RA clinical manifestations, a disease activity score of 28 (DAS28) according to EULAR criteria and DMARD-naïve status [44].

\subsection{Exclusion Criteria}

The exclusion criteria for this study included severe cardiovascular disease (congestive heart failure, uncontrolled hypertension, coronary disease, severe arrhythmia), hypercholesterolemia or diabetes mellitus; hematopoietic, lung, hepatic or renal disorders; active bacterial or viral infections; other autoimmune diseases; treatment with steroids, immunosuppressors or other drugs that interact with the immune system in the previous 6 months; possible pregnancy or lactation during the 6-month study period; simultaneous malignancy; malnutrition; and congenital immunodeficiency.

\subsection{Study Protocol}

All patients were treated weekly for 6 months with $15 \mathrm{mg}$ oral MTX, adjusted by increments of $5 \mathrm{mg}$ to 25-30 weekly until disease response criteria were met (or not in non-responders), plus $5 \mathrm{mg}$ folic acid weekly. Patients were advised to take non-steroidal anti-inflammatory drugs at fixed doses during the study. All were monitored monthly to check for clinical and biochemical tolerance to MTX treatment, and at 3 and 6 months to assess the clinical response to treatment and to undertake immunological studies. Disease activity was determined using the DAS28 score according to EULAR criteria and the patient quality of life was measured using a validated Spanish version of the Health Assessment Questionnaire (HAQ) [45]. The clinical response of the patients to MTX treatment was defined according to EULAR criteria for RA [46], classifying patients as responders or non-responders. The responder group included those patients with a DAS28 score of $<3.2$, plus a DAS28 score after 6 months of MTX treatment that had fallen by at least 1.2 with respect to the initial score.

\subsection{Isolation and Analysis of Peripheral Blood Mononuclear Cells}

Three peripheral blood samples were taken from each patient by antecubital venipuncture at baseline (before starting MTX treatment) and at 3 months and 6 months after starting MTX treatment. Peripheral blood mononuclear cells (PBMC) were separated out by Ficoll-Hypaque (Lymphoprep ${ }^{\mathrm{TM}}$, Axis-Shield, Oslo, Norway) gradient centrifugation [47]. They were then resuspended in RPMI 1640 medium (Biowhittaker Products, Verviers, Belgium) supplemented with 10\% heat-inactivated fetal calf serum, $25 \mathrm{mM}$ Hepes (Biowhittaker Products) and 1\% penicillin-streptomycin (Biowhittaker Products). Cell enumeration was performed by conventional light microscopy using a Neubauer chamber, following trypan blue exclusion criteria for the identification of dead cells. The viability of 
fresh PBMC was checked by both trypan blue (light microscopy) and 7-aminoactinomycin D (7-AAD) (flow cytometry) exclusion.

$\mathrm{T}$ cells were phenotypically analyzed by nine-color polychromatic flow cytometry in a FACSAria-II flow cytometer running FACSDiva software (Becton-Dickinson, La Jolla, CA, USA). Two stained protocols were used. First, PBMCs were incubated with the next surface-labeled monocolonal antibodies CD3-Alexa700 (allophycocyanin Alexa 700, Becton-Dickinson), CD4-Percp (peridinin chlorophyll protein, Becton-Dickinson), CD45RA-APC (allophycocyanin, Becton-Dickinson), CCR7-PE-CY7 (phycoerythrin-cyanine 7, Becton-Dickinson) and CD28-FITC (fluorescein isothiocyanate, Becton-Dickinson) to study activation/differentiation stages of CD4+ T lymphocytes in combined of CD28 costimulatory receptor. Second, PBMCs were stained using labeled antibodies against the next surface antigens CD3, CD4, CD45RA and CCR7, CD3-Alexa700 (Becton-Dickinson), CD4-Percp (Becton-Dickinson), CD45RA-APC (Becton-Dickinson), CCR7-PE-CY7 (Becton-Dickinson) in combination with three $\mathrm{V} \beta$ (FITC, PE and FITC/PE, phycoerythrin, Beckman-Coulter International, Krefeld, Switzerland) until the 24 TCR V $\beta$ analyzed were reached. Thus, the $24 \mathrm{~V} \beta$ studied were 7.1, $16,20,8,12,1,22,4 \mathrm{~V} \beta$ for FITC, 5.3, 9, 18, 13.1, 5.2, 23, 11, $13.2 \mathrm{~V} \beta$ for PE and 3, 17, 5.1, 13.6, 2, 21.3, 14, 7.2 V $\beta$ for FITC/PE. A representative study of the gating strategy and the 24 TCR V $\beta$ repertoire on CD4+ T lymphocytes and their activated stages by flow cytometry is shown in Figure 1.
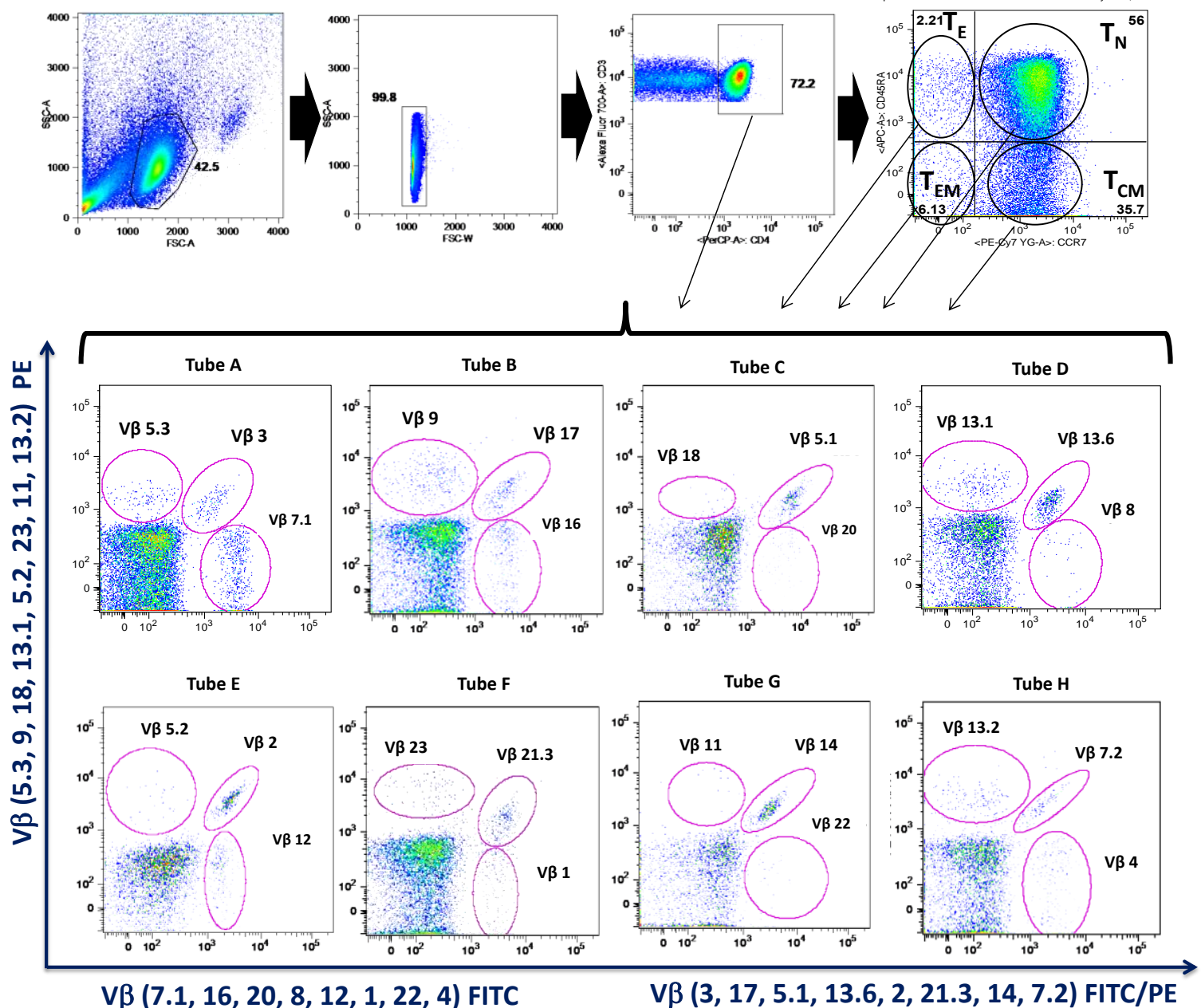

$\mathrm{V} \beta(7.1,16,20,8,12,1,22,4)$ FITC

$V \beta(3,17,5.1,13.6,2,21.3,14,7.2)$ FITC/PE

Figure 1. Study of the TCR V $\beta$ s repertoire gating strategy on CD4+ T lymphocytes. Note. Dot plots represent the gating strategy and all TCR V $\beta$ s repertoire evaluated in this study. Three V $\beta$ are studied in FITC, PE or a combination of both fluorochromes in each activation/differentiation stages of CD4 ${ }^{+}$ T lymphocytes. 
All samples were acquired in a FacsAria-II flow cytometer with four lasers. The filter configuration and fluorochrome combinations were as follows: for the Violet laser $(405 \mathrm{~nm}, 100 \mathrm{~mW})$, Aqua probe (560/20); for the blue laser (488 nm, $100 \mathrm{~mW}$ ) FITC (515/20) and PERCP (670/30); for the red yellow laser (561 nm, $100 \mathrm{~mW})$ PE (582/15) and PE-CY7 (780/60); for the red laser (640 nm, $60 \mathrm{~mW}$ ) APC (670/30); APC-Alexa 700 (730/45), APC-Alexa 750 (780/60). The staining protocol and quality and analysis controls were performed by 'fluorescence minus one control' as described by Roederer et al. [48]; the flow cytometry results are presented following the guidelines of the International Society of Advancement of Cytometry (ISAC) [49]. Samples were analyzed using FacsDiva 6.0 and Flow-Jo 7.0 software.

\subsection{Statistical Analysis}

Analyses were performed using SPSS-19 software (Statistical Package for the Social Sciences, SPSS-IBM, Armonk, NY, USA). Since most variables did not fulfill the normality hypothesis, the Mann-Whitney U-test for non-parametric data was used to analyze differences between groups, and analysis of variance followed by Wilcoxon tests was used for within group analyses. To assess the value of baseline circulating T CD4+ lymphocytes and their different subsets as predictors of MTX treatment response at baseline, 3 or 6 months after MTX treatment, receiver operating characteristic (ROC) curve analyses were performed, and the respective areas under the curves (AUC) determined. The best predictive cut-off value was defined as that which gave the highest product of sensitivity, specificity, positive predictive value (PPV) and negative predictive value (NPV). The significance level was set at $p<0.05$.

\section{Results}

\subsection{Patient Characteristics at Baseline}

Table 1 shows the baseline characteristics of the recently diagnosed DMARD-naïve patients who eventually became responders $(n=48)$ or non-responders $(n=20)$ after six months of MTX treatment. No significant differences were seen in terms of age or sex distribution between these groups of patients with respect to any clinical or analytical variable examined. After six months of MTX treatment, the responders, however, showed a significant reduction in CRP (from $15.40 \pm 6.51 \mathrm{mg} / \mathrm{dL}$ to $5.41 \pm 2.52 \mathrm{mg} / \mathrm{dL}$ ), in DAS28 (from $3.61 \pm 0.62$ to $2.35 \pm 0.33$ ), and in HAQ (from $0.82 \pm 0.51$ to $0.48 \pm 0.42$ ). The non-responders also showed a significant reduction in CRP (from $16.51 \pm 6.11 \mathrm{mg} / \mathrm{dL}$ to $8.96 \pm 4.21$ ), but the reductions noted in DAS28 (from $3.75 \pm 0.65$ to $3.52 \pm 0.29$ ) and HAQ (from $0.81 \pm 0.55$ to $0.76 \pm 0.66$ ) were, however, not significant.

Table 1. Patient demographic, clinical and biological characteristics at baseline.

\begin{tabular}{cccc}
\hline Variables & $\begin{array}{c}\text { Healthy Controls }(\mathbf{n}=\mathbf{2 4}) \\
(\mathbf{m e a n} \pm \mathbf{S D})\end{array}$ & $\begin{array}{c}\text { Eventual Responders }(\mathbf{n}=\mathbf{4 8}) \\
(\mathbf{m e a n} \pm \mathbf{S D})\end{array}$ & $\begin{array}{c}\text { Eventual } \\
\text { Non-Responders } \\
(\mathbf{n}=\mathbf{2 0})(\mathbf{m e a n} \pm \mathbf{S D})\end{array}$ \\
\hline Age (years) & $49.30 \pm 8.40$ & $51.05 \pm 9.72$ & $52.80 \pm 9.75$ \\
Sex (women) & $70.83 \%$ & $72.91 \%$ & $75.00 \%$ \\
CRP (mg/dL) & & $15.40 \pm 6.51$ & $16.51 \pm 6.11$ \\
Rheumatoid factor (+) & $90.76 \%$ & $92185 \%$ \\
Anti-CCP (UI/mL) & & $425.61 \pm 389.25$ & $433.99 \pm 295.60$ \\
DAS28 & $3.61 \pm 0.62$ & $3.75 \pm 0.65$ \\
Erosions (+) & $26.17 \%$ & $27.07 \%$ \\
HAQ & & $0.82 \pm 0.51$ & $0.81 \pm 0.55$ \\
\hline
\end{tabular}

CRP, C-reactive protein; anti-CCP, anti-cyclic citrullinated peptide antibody; DAS28, Disease Activity Score 28; HAQ, Health Assessment Questionnaire. The data represent the demography and clinical characteristics of RA patients according to their response to MTX at baseline of MTX treatment. All values are expressed as mean \pm SD. 
3.2. Recently Diagnosed, Dmard-Nä̈ve Ar Patients Showed Increased Numbers of $T_{n}, T_{e m}$ and $C d 4+T_{e}$ and Cd4+Cd28-T Lymphocytes,

At baseline, recently diagnosed DMARD-naive RA patients showed a significant increase in the circulating CD4+ T lymphocyte counts with respect to healthy controls (Table 2). This expansion of circulating CD4+ T lymphocyte is explained by a significant increase in the counts of CD4+ $T_{N}, T_{E M}$ and $\mathrm{CD} 4+\mathrm{T}_{\mathrm{E}}$ lymphocytes in recently diagnosed DMARD-naive RA patients. In addition, the number and percentage of circulating CD4+CD28- T lymphocytes was significantly increased in RA patients with respect to healthy controls. The main expansion of CD28- T cells was found in the CD4+ $T_{E}$ subset from recently diagnosed DMARD-naive RA patients.

Table 2. Activation/differentiation stage of CD4 T lymphocyte subsets in the recently diagnosed DMARD-naïve patients at baseline.

\begin{tabular}{|c|c|c|c|c|c|}
\hline $\mathrm{n}^{\circ} / \mu \mathrm{L}(\%)$ & Controls & $\begin{array}{c}\text { Patients at } \\
\text { Baseline }\end{array}$ & & Controls & $\begin{array}{c}\text { Patients at } \\
\text { Baseline }\end{array}$ \\
\hline Subsets & \multicolumn{2}{|c|}{ CD4+ } & & \multicolumn{2}{|c|}{ CD4+CD28- } \\
\hline $\begin{array}{c}\text { CD4+ Total } \\
\text { (\% with respect to } \\
\text { total lymphocytes) }\end{array}$ & $\begin{array}{c}770.29 \pm 61.59 \\
(39.62 \pm 3.07)\end{array}$ & $\begin{array}{c}1265.96 \pm 95.10 * \\
(50.99 \pm 2.24)^{*}\end{array}$ & $\begin{array}{c}\text { (\% with respect } \\
\text { to total CD4+ } \\
\text { lymphocytes) }\end{array}$ & $\begin{array}{c}12.16 \pm 3.76 \\
(1.72 \pm 0.66)\end{array}$ & $\begin{array}{l}101.77 \pm 36.88 \text { * } \\
(10.10 \pm 4.14)^{*}\end{array}$ \\
\hline $\begin{array}{c}\mathrm{T}_{\mathrm{N}}(\% \text { with respect to } \\
\text { total CD4+ } \\
\text { lymphocytes })\end{array}$ & $\begin{array}{c}460.55 \pm 34.99 \\
(60.61 \pm 2.8)\end{array}$ & $\begin{array}{c}737.13 \pm 80.82 * \\
(58.58 \pm 4.00)\end{array}$ & $\begin{array}{l}\mathrm{T}_{\mathrm{N}}(\% \text { with } \\
\text { respect to total } \\
\mathrm{CD} 4+\mathrm{CD} 28- \\
\text { lymphocytes })\end{array}$ & $\begin{array}{c}1.8 \pm 0.45 \\
(0.40 \pm 0.12)\end{array}$ & $\begin{array}{l}2.87 \pm 0.57 \\
(0.7 \pm 0.2)\end{array}$ \\
\hline $\mathrm{T}_{\mathrm{EM}}$ & $\begin{array}{c}37.44 \pm 6.6 \\
(4.63 \pm 0.66)\end{array}$ & $\begin{array}{c}164.43 \pm 37.00 * \\
(12.58 \pm 3.07)\end{array}$ & $\mathrm{T}_{\mathrm{EM}}$ & $\begin{array}{c}5.25 \pm 2.31 \\
(14.00 \pm 4.5) \\
\end{array}$ & $\begin{array}{l}35.04 \pm 19.03 \\
(26.8 \pm 5.6)^{*}\end{array}$ \\
\hline $\mathrm{T}_{\mathrm{E}}$ & $\begin{array}{l}11.79 \pm 5.85 \\
(1.62 \pm 0.71)\end{array}$ & $\begin{array}{l}60.54 \pm 17.46^{*} \\
(5.40 \pm 1.31)^{*}\end{array}$ & $\mathrm{~T}_{\mathrm{E}}$ & $\begin{array}{c}4.24 \pm 2.09 \\
(46.89 \pm 8.81)\end{array}$ & $\begin{array}{l}62.54 \pm 28.98^{*} \\
(81.2 \pm 4.50)^{*}\end{array}$ \\
\hline $\mathrm{T}_{\mathrm{CM}}$ & $\begin{array}{l}260.5 \pm 31.23 \\
(33.14 \pm 2.07)\end{array}$ & $\begin{array}{c}303.84 \pm 37.62 \\
(23.42 \pm 1.38) *\end{array}$ & $\mathrm{~T}_{\mathrm{CM}}$ & $\begin{array}{c}0.85 \pm 0.41 \\
(0.50 \pm 0.30)\end{array}$ & $\begin{array}{l}1.31 \pm 0.52 \\
(0.6 \pm 0.30)\end{array}$ \\
\hline
\end{tabular}

Note. Values represent numbers (cells $/ \mu \mathrm{L}$ ) and percentages (in brackets) of naïve ( $\mathrm{T}_{\mathrm{N}}$ ) effector memory $\left(\mathrm{T}_{\mathrm{EM}}\right)$, effector $\left(T_{E}\right)$ and central memory $\left(T_{C M}\right)$ activation/differentiation stages of $C D 4+(T h)$ and $C D 4+C D 28-T$ lymphocytes in the DMARD-naïve patients $(n=68)$ and healthy controls $(n=24)$ at baseline. $\%$ of CD4+ total are expressed with respect of total lymphocytes, $\% \mathrm{CD} 4+\mathrm{CD} 28$ - with respect of total $\mathrm{CD} 4+$ and $\mathrm{T}_{\mathrm{N}}, \mathrm{T}_{\mathrm{EM}}, \mathrm{T}_{\mathrm{E}} \mathrm{y} \mathrm{T}_{\mathrm{CM}}$ with respect of total CD4+ or CD4+CD28-, respectively. All values are expressed as mean \pm S.E.M. ${ }^{*} p<0.05$.

\subsection{MTX Responder and Non-Responder Recently Diagnosed Ra Patients Showed Different CD4+ T Lymphocyte Distributions at Basal Conditions and after 3 and 6 Months of Treatment}

Before starting the MTX treatment, responder and non-responder patients showed a significant increase in circulating CD4+ T lymphocyte counts with respect to healthy donors but there were not significant differences between both groups of patients. However, after 6 months of MTX treatment, the non-responders showed a significant expansion of the CD4+ T lymphocyte population, and the responders normalized the CD4+ T lymphocyte counts (Figure 2A).

At baseline, responders showed a significant increase in the CD4+ $T_{N}$ lymphocyte counts with respect to non-responders and healthy controls. After 6 months of MTX treatment, a significant reduction and normalization in the $\mathrm{CD} 4+\mathrm{T}_{\mathrm{N}}$ counts was found in responders. In the non-responders, a significantly larger number of CD4+ $\mathrm{T}_{\mathrm{N}}$ cells were seen after 3 months of MTX treatment (Figure 2B).

At baseline and after 3 and 6 months of MTX treatment, the non-responders showed significantly larger $\mathrm{CD} 4+\mathrm{T}_{\mathrm{EM}}$ lymphocyte counts than responders and healthy donors. (Figure $2 \mathrm{C}$ ). The CD4+ $\mathrm{T}_{\mathrm{E}}$ lymphocyte counts were also significantly increased in both groups of patients with respect that found in healthy controls at baseline and after 3 and 6 months of MTX treatment. However, there were only significant differences in the $\mathrm{CD} 4+\mathrm{T}_{\mathrm{E}}$ lymphocyte counts between both groups of patients at baseline (Figure 2D). 

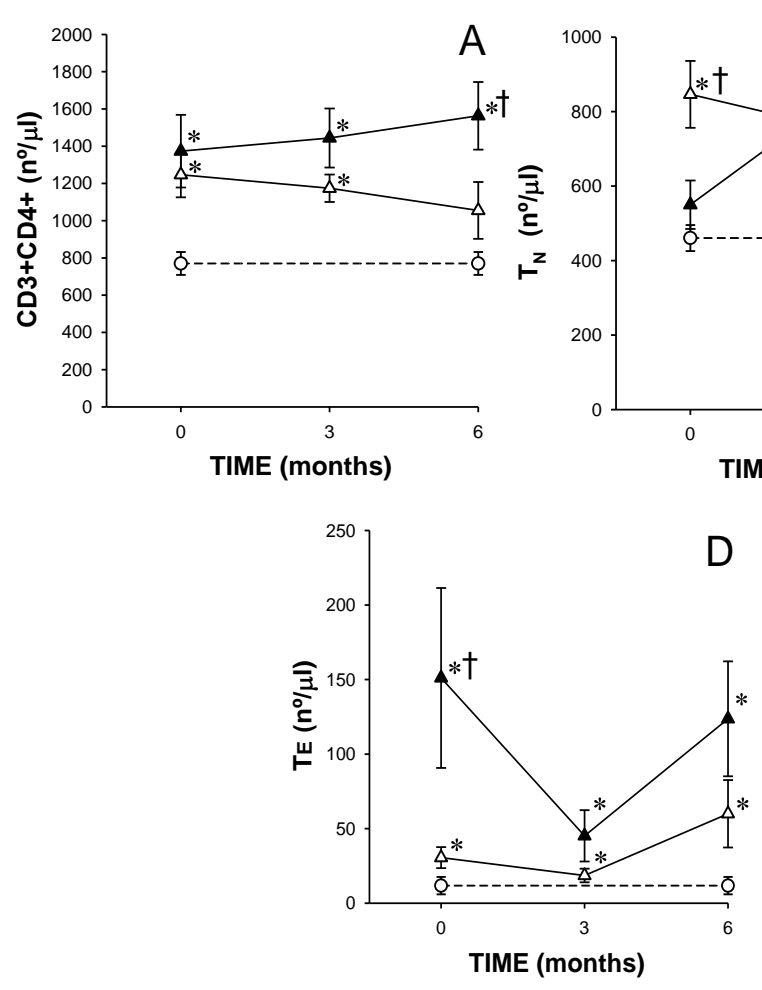
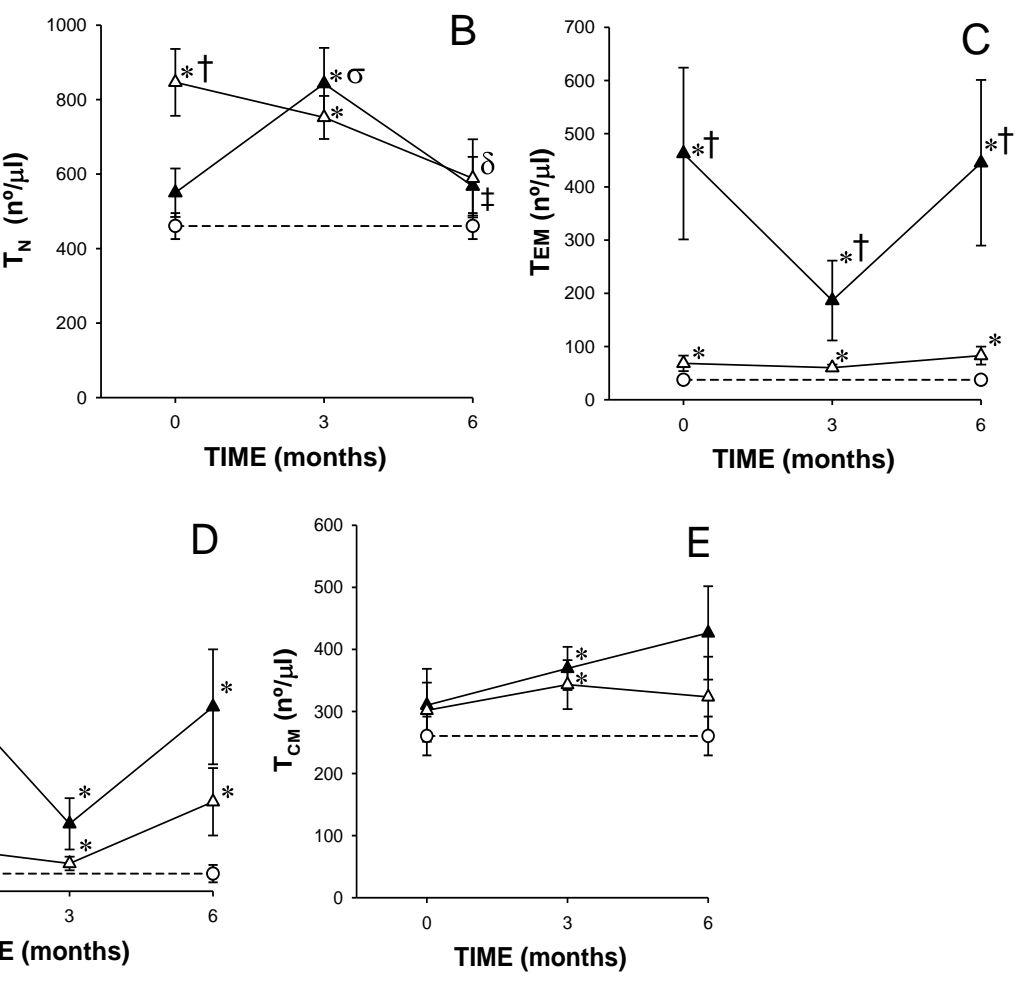

Figure 2. Panels A-E represents total and activation/differentiation stage subsets of CD4+ T lymphocytes in eventual responders and non-responders at baseline, and between responders and non-responders after 3 and 6 months of treatment. Note. Values represent numbers of naïve $\left(T_{N}\right)$, effector memory $\left(\mathrm{T}_{\mathrm{EM}}\right)$, effector $\left(\mathrm{T}_{\mathrm{E}}\right)$ and central memory $\left(\mathrm{T}_{\mathrm{CM}}\right) \mathrm{CD}^{+} \mathrm{T}$ cells from $(\Delta)$ responders (including eventual at baseline) and ( $\boldsymbol{\Lambda}_{\text {) }}$ non-responders (including eventual at baseline) at up to 6 months of MTX treatment. The dotted line represents the mean of the results obtained for each variable in this group of subjects in the three different studies performed $(\bigcirc)$. All values are expressed as mean cell counts \pm S.E.M. $*, p<0.05$ for responders or non-responders (including eventual) vs. healthy controls; $\dagger, p<0.05$ for responders vs. non-responders (including eventual), $\sigma, p<0.05$ for values at 3 months of treatment compared to baseline, $\ddagger, p<0.05$ at 6 months of treatment time compared to 3 months, and $\delta, p<0.05$ at 6 months of treatment time compared to baseline.

At baseline, responders and non-responders showed normal $\mathrm{CD} 4+\mathrm{T}_{\mathrm{CM}}$ lymphocyte counts. At 3 months, a significant increase in the $\mathrm{CD} 4+\mathrm{T}_{\mathrm{CM}}$ lymphocyte counts was observed in both groups of patients with respect to healthy controls (Figure 2E).

A representative dot plot of CD4+ T lymphocytes and their activation/differentiation stages expression from RA responder and non-responder patients at baseline and HCs is shown in Figure 3 .

The CD4+CD28- T lymphocyte counts were significantly increased in non-responders with respect to those found in responders and healthy controls at baseline (Figure 4A). However, non-responders showed a significant reduction in the CD4+CD28- T lymphocyte counts after 3 months of MTX treatment with a significant increase after 6 months of treatment. At baseline, non-responders showed a significant increase in the counts of $C D 4+C D 28-T_{E M}$ and $T_{E}$ with respect to responders (Figure $4 C, D$ ). However, after 6 months of treatment, non-responders had significant higher counts of CD4+CD28$\mathrm{T}_{\mathrm{N}}, \mathrm{T}_{\mathrm{EM}}$ and $\mathrm{T}_{\mathrm{E}}$ with respect to responders.

\subsection{The Number of Circulating CD4+ $T_{E M}$ Lymphocytes Predict the Clinical Response to MTX Treatment in} Recently Diagnosed Dmard-Naive Patients

Figure 5 shows the predictive value of the $\mathrm{CD} 4+\mathrm{T}_{\mathrm{EM}}$ lymphocyte counts with respect to clinical response to MTX. At baseline, a cut-off value of 273 cells/ $\mu$ l for circulating lymphocytes showed 
$100 \%$ sensitivity and $75 \%$ specificity in terms of discriminating between eventual responders and non-responders. The predictive values of the $C D 4+T_{N}$, and $T_{E}$ counts were inferior to those found for $\mathrm{T}_{\mathrm{EM}}$ (data not shown).

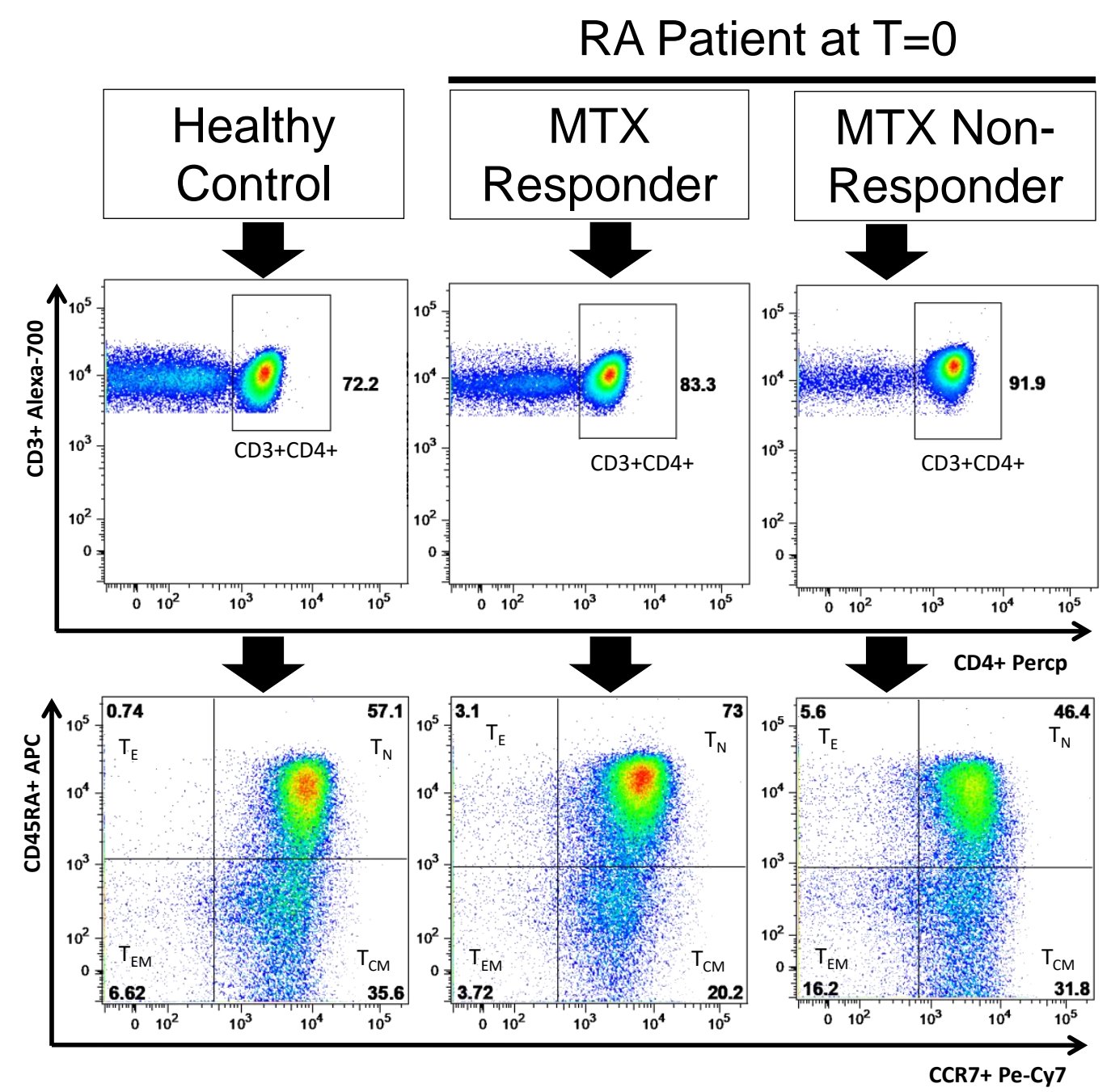

Figure 3. $\mathrm{CD}^{+} \mathrm{T}$ lymphocyte and their activation/differentiation stages in RA patients. Note. Dot plots represent the distribution of $\mathrm{T} \mathrm{CD}^{+}$in percentages of naïve $\left(\mathrm{T}_{\mathrm{N}}\right)$, central memory $\left(\mathrm{T}_{\mathrm{CM}}\right)$, effector memory $\left(\mathrm{T}_{\mathrm{EM}}\right)$ and effector $\left(\mathrm{T}_{\mathrm{E}}\right) \mathrm{CD}^{+} \mathrm{T}$ lymphocytes in a three representative situations: a healthy control, and a responder and non-responder RA patients at baseline of MTX treatment.

\subsection{MTX Responder and Non-Responder Recently Diagnosed Ar Patients Show Different Pattern of Distribution of the V $\beta$ T-Cell Repertoire in Circulating CD4+ T Lymphocyte}

We investigated the distribution of the $1,2,3,4,5.1,5.2,5.3,7.1,7.2,8,9,11,12,13.1,13.2,13.6,14$, $16,17,18,20,21.3,22$ and $23 \mathrm{~V} \beta$ receptor $\mathrm{T}$-cell repertoire families of the CD4+ $\mathrm{T}_{\mathrm{N}}, \mathrm{T}_{\mathrm{EM}}, \mathrm{T}_{\mathrm{E}}$ and $\mathrm{T}_{\mathrm{CM}}$ lymphocytes from MTX responder and non-responder recently diagnosed RA patients at baseline and after 6 months of treatment (Figure 6). We found an expansion of the V $\beta 8$ TCR family in the CD4+ $T_{E M}$ and $\mathrm{T}_{\mathrm{E}}$ lymphocyte subsets at both times of the study in responders with respect to non-responders and in the $\mathrm{T}_{\mathrm{N}}$ and $\mathrm{T}_{\mathrm{CM}}$ after 6 months of treatment. However, non-responders showed increased percentages of V $\beta 2$ TCR family in the $T_{E M}$ subset at both times of the study and in $T_{N}$ and $T_{C M}$ subsets after 6 months of treatment. Furthermore, non-responders showed enhanced percentages of the $V \beta 1$ and V $\beta 5.3$ families in the CD4+ $T_{E M}$ subsets at basal conditions and V $\beta 5.1$ family in the CD4+ $T_{E M}$ and $\mathrm{T}_{\mathrm{E}}$ subsets. 

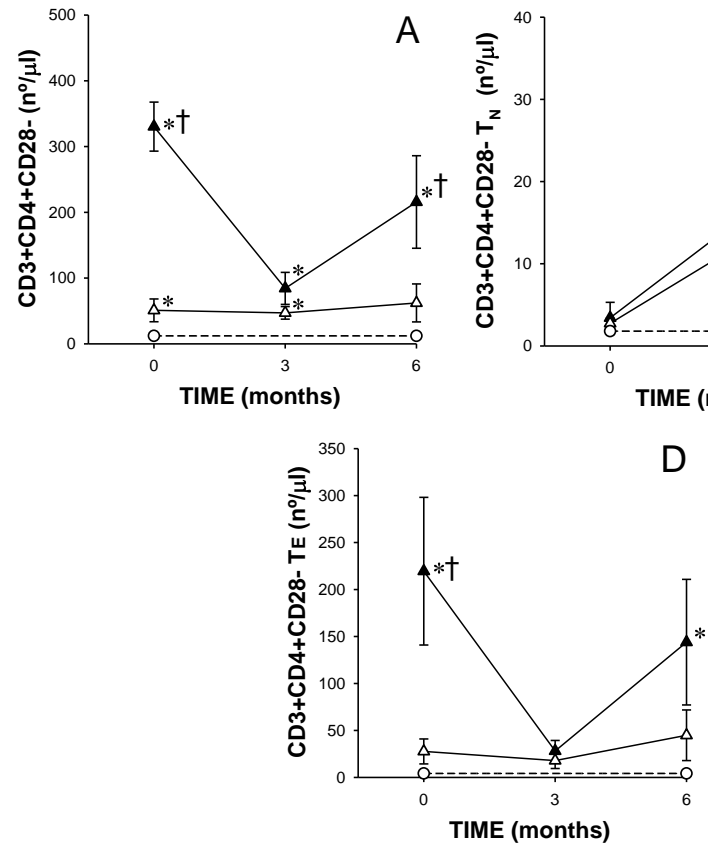

D
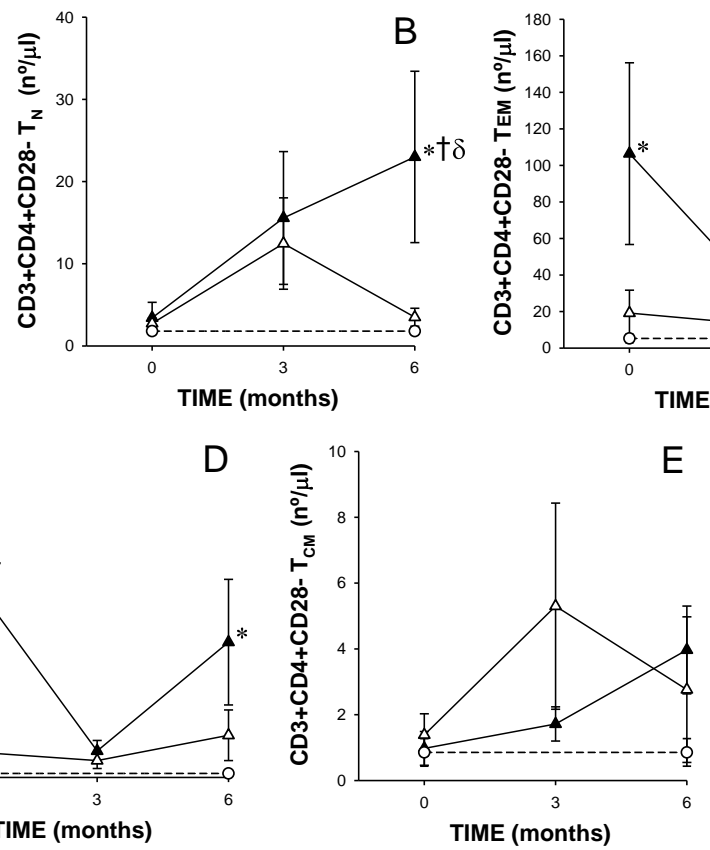

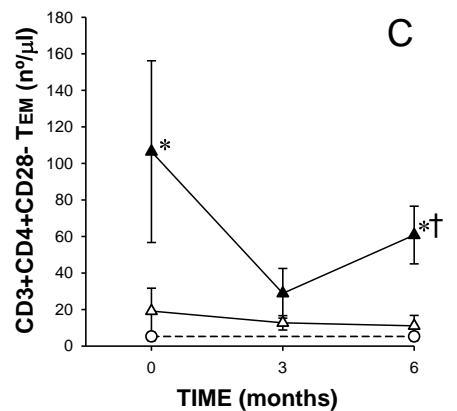

E

Figure 4. Panels A-E represents counts of CD4+CD28- T lymphocytes subsets in eventual responders and non-responders at baseline, and between responders and non-responders after 3 and 6 months of treatment. Note. Values represent numbers of total CD4+CD28- T lymphocytes and in their activation/differentiation stages $\left(\mathrm{T}_{\mathrm{N}}, \mathrm{T}_{\mathrm{EM}}, \mathrm{T}_{\mathrm{E}}\right.$ and $\left.\mathrm{T}_{\mathrm{CM}}\right)$ from $(\Delta$ ) responders (including eventual at baseline) and ( $\boldsymbol{\Lambda}_{\text {) }}$ non-responders (including eventual at baseline) at up to 6 months of MTX treatment. The dotted line represents the mean of the results obtained for each variable in this group of subjects in the three different studies performed $(\bigcirc)$. All values are expressed as mean cell counts \pm S.E.M. ${ }^{*}, p<0.05$ for responders or non-responders (including eventual) vs. healthy controls; $\dagger, p<0.05$ for responders vs. non-responders (including eventual), $\sigma p<0.05$ for values at 3 months of treatment compared to baseline, $\ddagger, p<0.05$ at 6 months of treatment time compared to 3 months, and $\delta, p<0.05$ at 6 months of treatment time compared to baseline.

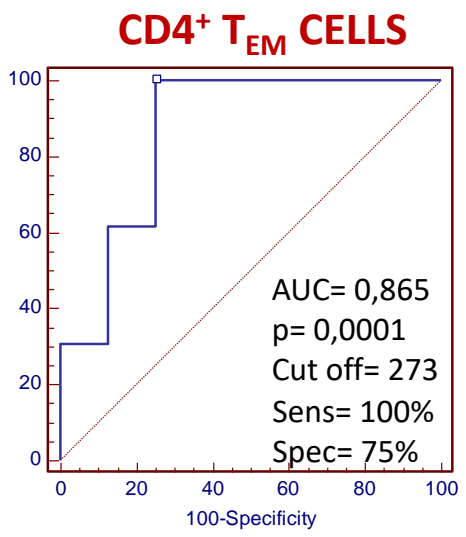

Figure 5. The receiver-operating characteristic (ROC) analysis of the counts of circulating CD4+ TEM lymphocytes at baseline of MTX treatment between responder and non-responder RA patients. Note. Receiver-operating characteristic (ROC) analysis of the counts of circulating CD4+ TEM lymphocytes. The predictive value of the absolute numbers of lymphocytes was determined by calculating the area under the curve (AUC). AUC and the optimum cut-offs (cells/ $\mu$ l) for distinguishing between MTX responders and non-responders, plus their sensitivity (Sens), specificity (Spec) values, are shown next to the curves. These were used to verify the validation of the ROC curves and to establish the predictive power of the cut-offs. The confidence intervals (C.I.) were 0.704 and 0.957 . 

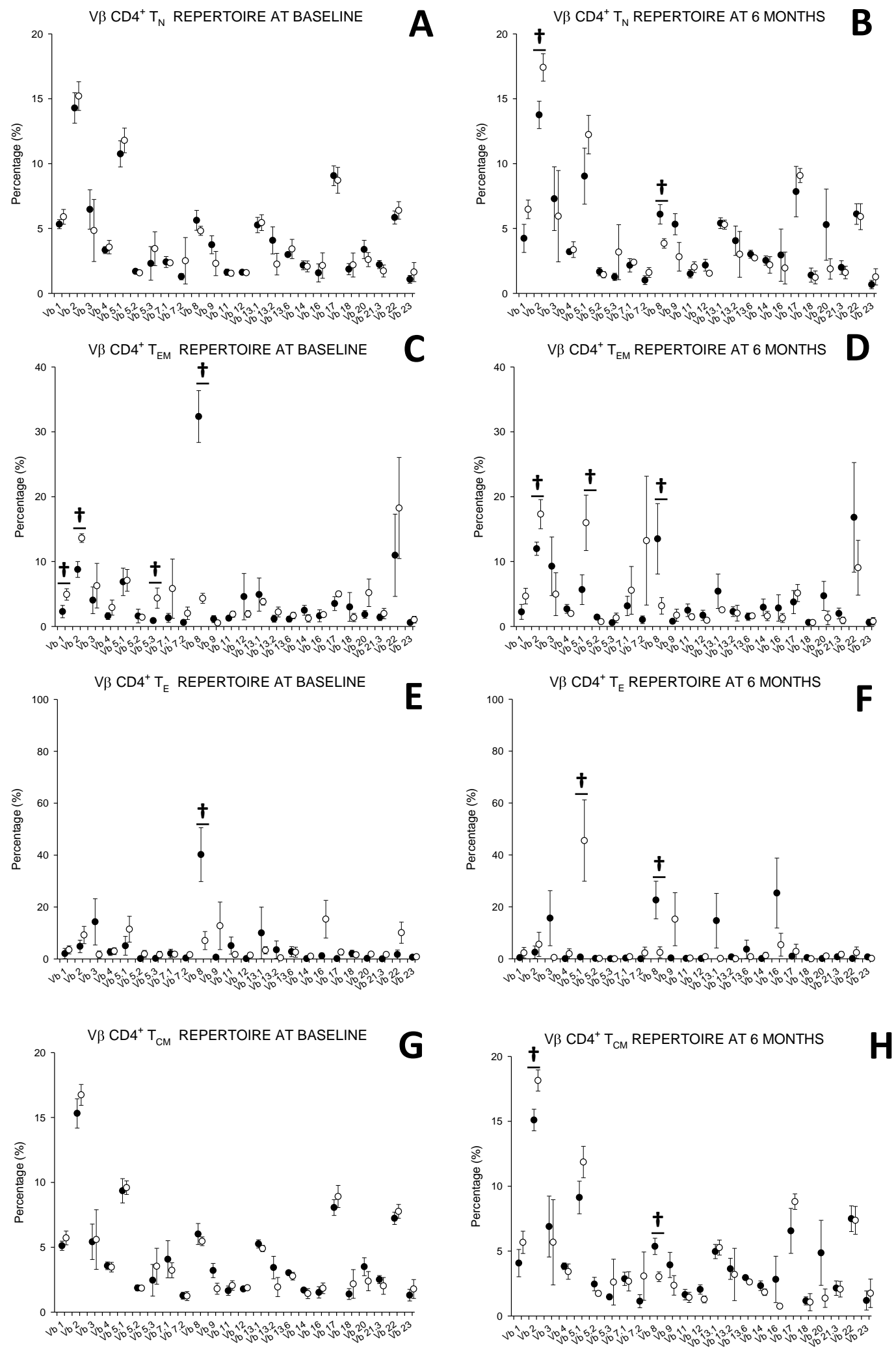

Figure 6. Panels A-H represents the TCR V $\beta$ distribution of $C D 4^{+} \mathrm{T}$ lymphocyte subsets in a responder and non-responder RA patients. Note. Data represent the TCR V $\beta$ distribution of naïve $\left(T_{N}\right)$, effector memory $\left(\mathrm{T}_{\mathrm{EM}}\right)$, effector $\left(\mathrm{T}_{\mathrm{E}}\right)$ and central memory $\left(\mathrm{T}_{\mathrm{CM}}\right) \mathrm{CD}^{+} \mathrm{T}$ cells from $({ })$ responders and $(\mathrm{O}$ ) non-responders at up to 6 months of MTX treatment. All values are expressed as percentages \pm S.E.M. $\dagger, p<0.05$ for responders vs. non-responders. 
A representative dot-plot of significantly $\mathrm{V} \beta$ repertoire distributions in $\mathrm{CD}^{+} \mathrm{T}_{\mathrm{EM}}$ lymphocytes in a responder (panel A) and non-responder (panel B) RA patients at baseline of MTX treatment is shown in Figure 7.

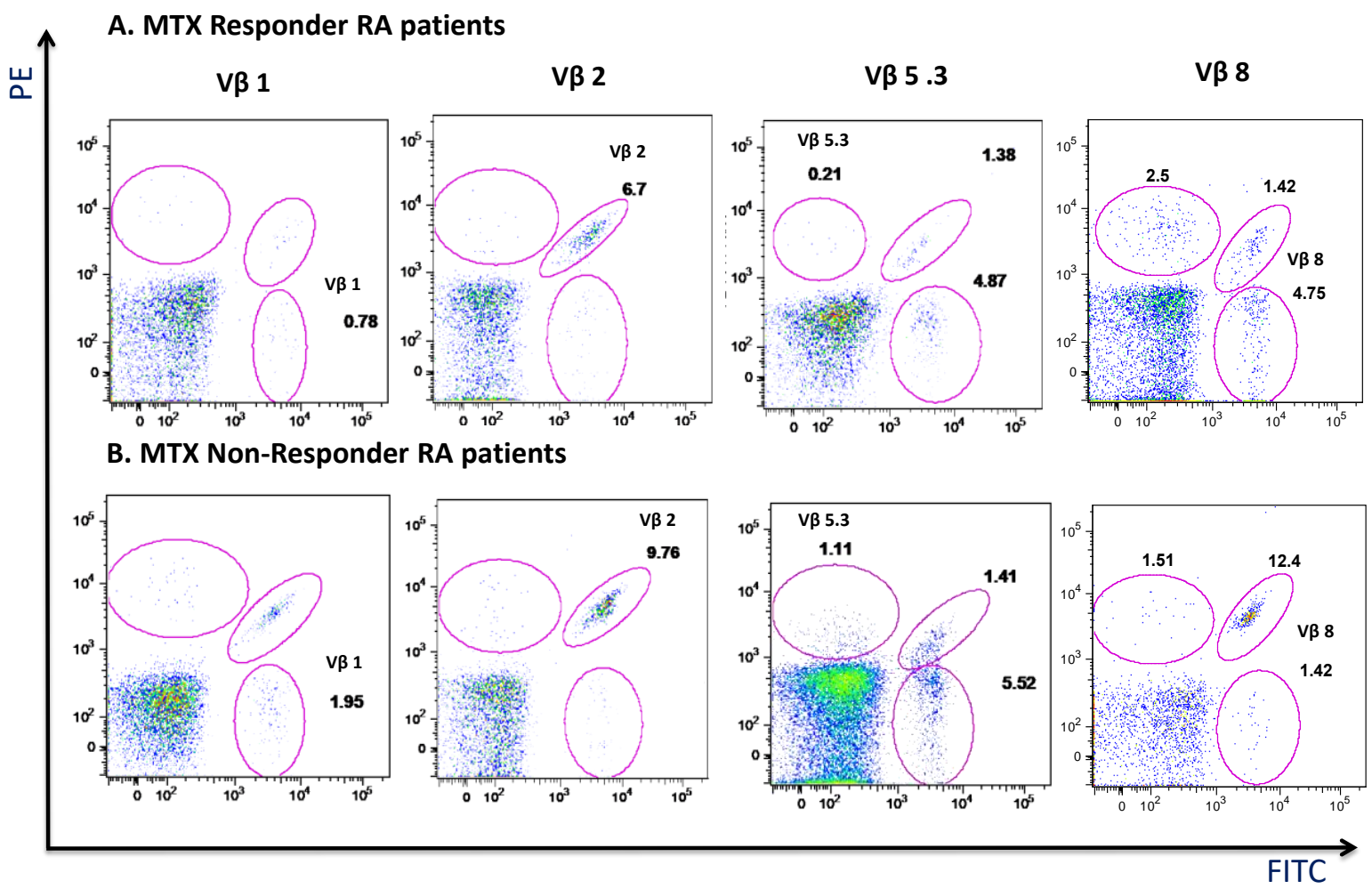

Figure 7. Representative dot-plot of $\mathrm{V} \beta$ expression in a responder and non-responder RA patients. Note. 1, 2, 5.3 and $8 \mathrm{~V} \beta$ repertoire distributions in $\mathrm{CD} 4^{+} \mathrm{T}_{\mathrm{EM}}$ lymphocytes in a representative responder (A) and non-responder (B) RA patients at baseline of MTX treatment.

\section{Discussion}

The pathogenesis of RA remains unclear, but the immune system appears to play a pivotal role in the induction and maintenance of joint and extra-musculoskeletal manifestations of the disease [50]. Indeed, T lymphocytes seem to be involved in initial and continuing joint damage, as well as in extra-articular events [51]. We focused our translational study in the characterization of the CD4+ $\mathrm{T}$ lymphocytes in a homogenous group of recently diagnosed DMARD-naïve RA patients before starting MTX and along the first six months of treatment. Two main scientific reasons supported this research strategy. We selected a population of recently diagnosed and DMARD-naïve RA patients for allowing the identification of alterations in circulating CD4+ lymphocytes that may be ascribed to the pathophysiology of the disease avoiding the potential effects of long-term inflammation, DMARDs and other immunomodulatory drugs and/or comorbidities. Second, we hypothesized that the pattern of alterations in the CD4 lymphocytes in DMARD-naïve RA patients might condition the response to DMARD and have potential relevance as a predictive biomarker of therapeutic response. Our data show marked CD4+ T lymphocytes alterations in DMARD-naïve RA patients and two different populations can be identified by the pattern of activation/differentiation CD4+ $\mathrm{T}$ subset redistribution and CD28 expression. Interestingly, these two groups of RA patients show different clinical response to MTX treatment. The increased number of circulating CD4+ T lymphocytes MTX responders can be mainly ascribed to the expansion of the $T_{N}$ but also show there is an increase in the counts of the minority $\mathrm{T}_{\mathrm{EM}}$ and $\mathrm{T}_{\mathrm{E}}$ subsets. The expansion of the $\mathrm{T}_{\mathrm{N}}$ found in the MTX responders might be related to an increased production of these cells and/or to a reduction in their consumption explained 
by a diminished antigenic/inflammatory stimulation. In contrast, a dramatic expansion of $\mathrm{T}_{\mathrm{EM}}$ and $\mathrm{T}_{\mathrm{E}}$ subsets is found in MTX non-responders. Interestingly, CD4+ $\mathrm{T}_{\mathrm{EM}}$ cells are characterized by their ability to enter inflamed non-lymphoid tissues [52-54]. Thus, the expansion of $\mathrm{T}_{\mathrm{EM}}$ observed in DMARD-naïve RA patients and mainly in those MTX non-responders may contribute to their reported presence in the inflamed synovial of these patients [55]. The observation of a reduction in the counts of circulating $\mathrm{T}_{\mathrm{N}} \mathrm{CD} 4+$ lymphocytes in long-disease-duration and DMARD-treated patients has supported the knowledge of a deficient function of the thymus in RA patients $[18,25]$. However, our findings show a normal or increased number of $\mathrm{T}_{\mathrm{N}} \mathrm{CD} 4+$ lymphocytes in DMARD-naïve RA patients. These data do not support the involvement of the thymus deficiency in the initial stage of the pathogenesis of the RA.

The different pattern of activation/differentiation CD4+ T subsets redistribution found in MTX responder and non-responder DMARD-naïve RA patients at basal conditions is differentially modified by the treatment. After six months of MTX treatment, non-responders remain with a marked expansion of the $\mathrm{T}_{\mathrm{EM}}$ subset as well as of the $\mathrm{T}_{\mathrm{EM}}$ cells conditioning the maintenance of increased counts of total circulating CD4+ lymphocytes.

Previous studies of the activation/differentiation CD4+ T subset distribution in RA patients have shown conflicting results [21-25]. Several reasons may be involved in this heterogeneity such as differences in disease duration, previous and active DMARD use, immunosuppressor treatments, associated comorbidities, and genetic and epidemiological characteristics. As previously indicated, to reduce the impact of potential interferences with the mechanisms directly associated with RA pathophysiology, we investigated a clinically homogeneous population of recently diagnosed, DMARD-naïve patients with RA. Furthermore, the accuracy of the methodologies employed for the CD4+ T lymphocyte analysis have been improved such as those used in this study. Our results agree with the recently reported expansion of $\mathrm{T}_{\mathrm{N}}$ and total $\mathrm{T}$ effector CD4+ in RA patients without DMARDs treatment in the previous three months to the study [56]. We have found that the pattern of activation/differentiation CD4+ T subset redistribution is different in MTX responders or non-responders at basal conditions and the variations observed along the treatment give a light to the understanding of the observed variation.

CD28 is a co-stimulatory molecule that plays multiple roles during $\mathrm{T}$ cell activation, proliferating, and survival [57]. A characteristic feature of long term activated and old T cells is the loss of the CD28 co-estimulatory receptor [57]. CD28 down regulation may result in reduced T-cell receptor activation and the release of certain proinflammatory cytokines [57,58]. Our results show clear differences in the numbers of CD28-CD4+ lymphocytes between both groups of responder and non-responder RA patients. At basal conditions, the DMARD-naïve patients of the MTX non-responder group show a selective marked expansion of the $C D 28-T_{E M}$ and $T_{E}$ subsets and after 6 months of treatment are also observed in $\mathrm{T}_{\mathrm{N}}$ and $\mathrm{T}_{\mathrm{E}}$ subsets. In contrast, MTX responders show normal counts of CD28- $\mathrm{T}_{\mathrm{N}}, \mathrm{T}_{\mathrm{EM}}$, $\mathrm{T}_{\mathrm{E}}$ and $\mathrm{T}_{\mathrm{CM}}$ at basal conditions as naïve DMARD patients as well as after 6 months of MTX treatment. These results agree with previous observations of expanded CD28-CD4 T lymphocytes in early and long term treated RA [59,60]. However, our results do not support the knowledge of the expansion of the CD28-CD4 T lymphocytes as an initial finding of RA since it is only observed in a defined group of patients.

The differences in the CD4+ T lymphocyte compartment between MTX responder and non-responder RA patients is also supported by the study of their V $\beta$ TCR repertoire. At basal conditions, MTX responders show an expansion of $\mathrm{V} \beta 8$ family expression on $\mathrm{T}_{\mathrm{EM}}$ cells with respect non-responders and after 6 months also is expanded in $T_{N}$ cells and $T_{M C}$ subsets. In contrast, MTX non-responders show an expansion of $\mathrm{V} \beta 1,2$, and 5.3 repertoire families in the $\mathrm{T}_{\mathrm{EM}}$ subset with respect to responders in basal conditions. However, after six months of the MTX treatment, non-responders showed an expansion of $\mathrm{V} \beta 2$ in $\mathrm{T}_{\mathrm{N}}, \mathrm{T}_{\mathrm{EM}}$ and $\mathrm{T}_{\mathrm{CM}}$, and $\mathrm{V} \beta 5.1$ in $\mathrm{T}_{\mathrm{EM}}$ and $\mathrm{T}_{\mathrm{E}}$. Thus, we have found different patterns of distribution of the $\mathrm{V} \beta \mathrm{TCR}$ repertoire families between the activation/differentiation $\mathrm{CD} 4+\mathrm{T}$ subsets in the MTX responder and non-responder patients and also along the evolution of 
the disease. These findings support the heterogeneity of the results described in previous studies of the V $\beta$ TCR repertoire in CD4+ lymphocytes in RA [30-43]. Our findings indicate the analysis has to specifically study the different CD4+ subsets, the stage of disease evolution and the pattern of clinical response to the DMARD treatment for obtaining accurate results of the TCR repertoire in CD4+ lymphocytes form RA patients. Previous molecular biology studies performed in whole CD4+ lymphocytes preparations have not selectively analyzed the different CD4+ subsets [34,61-64]. It has been postulated that the V $\beta 8$ family plays a pathogenic role in RA $[36,41,65,66]$. These studies have neither selectively analyze the expression of this family in the CD4+ subsets nor include DMARD naïve patients and compare the clinical evolution of the disease. Our findings of a clear expansion of $\mathrm{V} \beta 8$ family in $\mathrm{T}_{\mathrm{EM}}$ and $\mathrm{T}_{\mathrm{E}}$ subsets in basal conditions and also in $\mathrm{T}_{\mathrm{N}}$ and $\mathrm{T}_{\mathrm{CM}}$ after six months of treatment in MTX responder patients do not support the knowledge of the pathogenic role of this family in the first months of the disease. Moreover, an association between the expression of HLA-DR4 and the presence of the $V \beta 8$ family has been found [67]. The expansion of the V $\beta 2$ family has been reported in circulating and/or synovial fluid $\mathrm{T}$ lymphocytes or $\mathrm{CD} 4+$ population in a very limited number of RA patients [33,38,39].

Our data demonstrate that DMARD naïve RA patients have a disturbance of the CD4+ T lymphocytes but a different pattern of alteration is found in MTX responder and non-responders. The relevance of the differences in the CD4+ compartment found in both groups of patients is supported by the predictive value of MTX response of the CD4+ $\mathrm{T}_{\mathrm{EM}}$ lymphocyte counts in DMARD naïve RA patients. These findings expand the knowledge of a different pattern of alteration of circulating immune cells in MTX responder and non-responder DMARDs naïve RA patients [68]. The cause of the different modification of the CD4+ lymphocytes found in both groups of patients along the first six months of treatment remains elusive. It might be related to a differential sensitivity of these cells to the action of MTX in both groups of patients and/or to the level of control of the inflammatory progression of the disease. The analysis of the spontaneous evolution of the CD4+ lymphocytes in untreated DMARD patients is not ethically supported. The long term follow up of the patients and the response to other treatments in MTX non-responders might give new clues for the understanding of the pathogenic and clinical relevance of the alterations observed in the CD4+ lymphocytes of RA patients at the first months of evolution and treatment. The study of a potential different pattern of CD4 alterations between MTX responders and non-responders to other DMARDs or biologic DMARDs is also of interest. It has been previously that monocyte populations are markers of response to adalimumab in MTX non-responder patients [69].

Author Contributions: M.A.-M. and J.M. were responsible for the study's conception and design, J.M. and A.M.G. for data acquisition, and M.A.-M., J.M., D.D., C.B., A.T., A.P., L.R., L.C., A.I.S. and F.A. for data analysis and interpretation. J.M., M.A.-M., C.B. and I.S. drafted the manuscript. All authors read and approved the final manuscript.

Funding: This work was partially supported by grants from the Fondo de Investigación de la Seguridad Social, Instituto de Salud Carlos III (PI18/01726), Spain and the Programa de Actividades de I+D de la Comunidad de Madrid en Biomedicina (B2017/BMD-3804), Madrid, Spain, and IRYCIS, Ciberehd isciii, Ministerio de Salud, Spain.

Acknowledgments: The authors would like to thank all the medical doctors, nurses and technical staff of the Immune System Diseases-Rheumatology Service of the Hospital Universitario Principe de Asturias and the Department of Medicine of the University of Alcalá for their careful and generous collaboration while doing this work.

Conflicts of Interest: The authors declare themselves free of competing interests. 


\section{Abbreviations}

$\begin{array}{ll}\text { DAS28 } & \text { Disease Activity Score 28 } \\ \text { DMARDS } & \text { disease-modifying antirheumatic drugs } \\ \text { EULAR } & \text { European League Against Rheumatism } \\ \text { HAQ } & \text { Health Assessment Questionnaire } \\ \text { mAb } & \text { monoclonal antibodies } \\ \text { PBMC } & \text { peripheral blood mononuclear cells } \\ \text { FITC } & \text { fluorescein-isothiocyanate } \\ \text { PE } & \text { phycoerythrin } \\ \text { PerCP } & \text { peridinin chlorophyll protein conjugate } \\ \text { APC } & \text { allophycocyanin } \\ \text { APC-Alexa780 } & \text { allophycocyanin-alexa-780 } \\ \text { PE-CY7 } & \text { phycoerythrin-cyanine seven } \\ \text { RA } & \text { rheumatoid arthritis } \\ \text { RPMI } & \text { Roswell Park Memorial Institute } \\ \text { SD } & \text { standard desviation } \\ \text { S.E.M. } & \text { standard error of the mean }\end{array}$

\section{References}

1. Scott, D.L.; Wolfe, F.; Huizinga, T.W. Rheumatoid arthritis. Lancet 2010, 376, 1094-1098. [CrossRef]

2. Gibbons, L.J.; Hyrich, K.L. Biologic Therapy for Rheumatoid Arthritis: Clinical Efficacy and Predictors of Response; Springer: Berlin/Heidelberg, Germany, 2009; Volume 23, pp. 111-124.

3. Smolen, J.S.; Landewe, R.; Breedveld, F.C. C. EULAR recommendations for the management of rheumatoid arthritis with synthetic and biological disease-modifying antirheumatic drugs: 2013 Update. Ann. Rheum. Dis. 2014, 73, 492-509. [CrossRef] [PubMed]

4. Rau, R. Efficacy of methotrexate in comparison to biologics in rheumatoid arthritis. Clin. Exp. Rheumatol. 2010, 28, S58-S64. [PubMed]

5. Bansard, C.; Lequerre, T.; Daveau, M. Can rheumatoid arthritis responsiveness to methotrexate and biologics be predicted? Rheumatology (Oxford) 2009, 48, 1021-1028. [CrossRef] [PubMed]

6. Alzabin, S. Williams RO Effector T cells in rheumatoid arthritis: Lessons from animal models. Febs Lett. 2011, 585, 3649-3659. [CrossRef] [PubMed]

7. Cope, A.P. T cells in rheumatoid arthritis. Arthritis Res. 2008, 10, 4-11. [CrossRef] [PubMed]

8. Weyand, C.M.; Bryl, E.; Goronzy, J.J. The role of T cells in rheumatoid arthritis. Arch. Immunol. Exp. (Warsz) 2000, 48, 429-435.

9. Mahnke, Y.D.; Brodie, T.M.; Sallusto, F.; Roederer, M.; Lugli, E. The who's who of T-cell differentiation: Human memory T-cell subsets. Eur. J. Immunol. 2013, 43, 2797-2809. [CrossRef]

10. Moro-Garcia, M.A.; Alonso-Arias, R.; Lopez-Larrea, C. When Aging Reaches CD4+ T-Cells: Phenotypic and Functional Changes. Front. Immunol. 2013, 4, 107. [CrossRef]

11. Maecker, H.T.; McCoy, J.P.; Nussenblatt, R. Standardizing immunophenotyping for the Human Immunology Project. Nat. Rev. Immunol. 2012, 12, 191-200. [CrossRef]

12. Kaech, S.M.; Wherry, E.J. Ahmed R Effector and memory T-cell differentiation: Implications for vaccine development. Nat. Rev. Immunol. 2002, 2, 251-262. [CrossRef]

13. Sallusto, F.; Geginat, J.; Lanzavecchia, A. Central memory and effector memory T cell subsets: Function, generation, and maintenance. Annu. Rev. Immunol. 2004, 22, 745-763. [CrossRef]

14. Taylor, J.J.; Jenkins, M.K. CD4+ memory T cell survival. Curr Opin Immunol 2011, 23, 319-323. [CrossRef]

15. Sallusto, F.; Lanzavecchia, A. Heterogeneity of CD4+ memory T cells: Functional modules for tailored immunity. Eur. J. Immunol. 2009, 39, 2076-2082. [CrossRef]

16. Choy, E. Understanding the dynamics: Pathways involved in the pathogenesis of rheumatoid arthritis. Rheumatology (Oxford) 2012, 51, 3-11. [CrossRef]

17. Goronzy, J.J.; Lee, W.W. Weyand CM Aging and T-cell diversity. Exp. Gerontol. 2007, 42, 400-406. [CrossRef]

18. Koetz, K.; Bryl, E.; Spickschen, K.; O'Fallon, W.M.; Goronzy, J.J. Weyand CM T cell homeostasis in patients with rheumatoid arthritis. Proc. Natl. Acad. Sci. USA 2000, 97, 9203-9208. [CrossRef] 
19. Pawlowska, J.; Smolenska, Z.; Daca, A.; Witkowski, J.M.; Bryl, E. Older age of rheumatoid arthritis onset is associated with higher activation status of peripheral blood CD4(+) T cells and disease activity. Clin. Exp. Immunol. 2011, 163, 157-164. [CrossRef]

20. Salazar-Fontana, L.I.; Sanz, E.; Merida, I. Cell surface CD28 levels define four CD4+ T cell subsets: Abnormal expression in rheumatoid arthritis. Clin. Immunol. 2001, 99, 253-265. [CrossRef]

21. Fekete, A.; Soos, L.; Szekanecz, Z. Disturbances in B- and T-cell homeostasis in rheumatoid arthritis: Suggested relationships with antigen-driven immune responses. J. Autoimmun. 2007, 29, 154-163. [CrossRef]

22. Kohem, C.L.; Brezinschek, R.I.; Wisbey, H.; Tortorella, C.; Lipsky, P.E. Oppenheimer-Marks N Enrichment of differentiated CD45RBdim. Arthritis Rheum. 1996, 39, 844-854. [CrossRef]

23. Neidhart, M.; Pataki, F.; Schonbachler, J. Bruhlmann P Flow cytometric characterisation of the "false naive" (CD45RA+, CD45RO-, CD29 bright+) peripheral blood T-lymphocytes in health and in rheumatoid arthritis. Rheumatol. Int. 1996, 16, 77-87. [CrossRef]

24. Neidhart, M.; Fehr, K.; Pataki, F. Michel BA The levels of memory (CD45RA-, RO+) CD4+ and CD8+ peripheral blood T-lymphocytes correlate with IgM rheumatoid factors in rheumatoid arthritis. Rheumatol. Int. 1996, 15, 201-209. [CrossRef]

25. Ponchel, F.; Morgan, A.W.; Bingham, S.J. Dysregulated lymphocyte proliferation and differentiation in patients with rheumatoid arthritis. Blood 2002, 100, 4550-4556. [CrossRef]

26. Schmidt, D.; Goronzy, J.J. Weyand CM CD4+ CD7. J. Clin. Invest. 1996, 97, 2027-2037. [CrossRef]

27. Goronzy, J.J.; Shao, L. Weyand CM Immune aging and rheumatoid arthritis. Rheum. Dis. Clin. North Am. 2010, 36, 297-310. [CrossRef]

28. Prescott, J.; Karlson, E.W.; Orr, E.H.; Zee, R.Y.; De V, I. Costenbader KH A Prospective Study Investigating Prediagnostic Leukocyte Telomere Length and Risk of Developing Rheumatoid Arthritis in Women. J. Rheumatol. 2016, 43, 282-288. [CrossRef]

29. Davis, M.M.; Bjorkman, P.J. T-cell antigen receptor genes and T-cell recognition. Nature 1988, 334, $395-402$. [CrossRef]

30. Liu, X.; Zhang, W.; Zhao, M. T cell receptor beta repertoires as novel diagnostic markers for systemic lupus erythematosus and rheumatoid arthritis. Ann. Rheum. Dis. 2019, 78, 1070-1078. [CrossRef]

31. Sun, W.; Nie, H.; Li, N. Skewed T-cell receptor BV14 and BV16 expression and shared CDR3 sequence and common sequence motifs in synovial T cells of rheumatoid arthritis. Genes Immun. 2005, 6, 248-261. [CrossRef]

32. Jia, X.; Wang, B.; Zhai, T.; Yao, Q.; Li, Q.; Zhang, J.A. T cell receptor revision and immune repertoire changes in autoimmune diseases. Clin. Immunol. 2018. [CrossRef]

33. Davey, M.P.; Munkirs, D.D. Patterns of T-cell receptor variable beta gene expression by synovial fluid and peripheral blood T-cells in rheumatoid arthritis. Clin. Immunol. Immunopathol. 1993, 68, 79-87. [CrossRef]

34. Genevee, C.; Diu, A.; Nierat, J. An experimentally validated panel of subfamily-specific oligonucleotide primers (V alpha 1-w29/V beta 1-w24) for the study of human $\mathrm{T}$ cell receptor variable $\mathrm{V}$ gene segment usage by polymerase chain reaction. Eur. J. Immunol. 1992, 22, 1261-1269. [CrossRef]

35. Goronzy, J.J.; Zettl, A. Weyand CM T cell receptor repertoire in rheumatoid arthritis. Int. Rev. Immunol. 1998, 17, 339-363. [CrossRef]

36. Hall, F.C.; Thomson, K.; Procter, J.; McMichael, A.J. Wordsworth BP TCR beta spectratyping in RA: Evidence of clonal expansions in peripheral blood lymphocytes. Ann. Rheum. Dis. 1998, 57, 319-322. [CrossRef]

37. Klarenbeek, P.L.; de Hair, M.J.; Doorenspleet, M.E. Inflamed target tissue provides a specific niche for highly expanded T-cell clones in early human autoimmune disease. Ann. Rheum. Dis. 2012, 71, 1088-1093. [CrossRef]

38. Pluschke, G.; Ginter, A.; Taube, H.; Melchers, I.; Peter, H.H. Krawinkel U Analysis of T cell receptor V beta regions expressed by rheumatoid synovial T lymphocytes. Immunobiology 1993, 188, 330-339. [CrossRef]

39. Sottini, A.; Imberti, L.; Bettinardi, A.; Mazza, C.; Gorla, R.; Primi, D. Selection of T lymphocytes in two rheumatoid arthritis patients defines different T-cell receptor V beta repertoires in CD4+ and CD8+ T-cell subsets. J. Autoimmun. 1993, 6, 621-637. [CrossRef]

40. Spreafico, R.; Rossetti, M.; van, L.J. A circulating reservoir of pathogenic-like CD4+ T cells shares a genetic and phenotypic signature with the inflamed synovial micro-environment. Ann. Rheum. Dis. 2016, 75, 459-465. [CrossRef] 
41. Striebich, C.C.; Falta, M.T.; Wang, Y.; Bill, J.; Kotzin, B.L. Selective accumulation of related CD4+ T cell clones in the synovial fluid of patients with rheumatoid arthritis. J. Immunol. 1998, 161, 4428-4436.

42. Zagon, G.; Tumang, J.R.; Li, Y.; Friedman, S.M. Crow MK Increased frequency of V beta 17-positive T cells in patients with rheumatoid arthritis. Arthritis Rheum. 1994, 37, 1431-1440. [CrossRef]

43. Zhou, J.; Kong, C.; Yu, J.; Dong, H.; Jin, C. Song Q Skewness of TCR Vbeta of peripheral blood and synovial fluid of patients with rheumatoid arthritis. J. Immunoass. Immunochem. 2014, 35, 207-219. [CrossRef]

44. Aletaha, D.; Neogi, T.; Silman, A.J. 2010 Rheumatoid arthritis classification criteria: An American College of Rheumatology European League Against Rheumatism collaborative initiative. Arthritis Rheum. 2010, 62, 2569-2581. [CrossRef]

45. Gonzalez, V.M.; Stewart, A.; Ritter, P.L.; Lorig, K. Translation and validation of arthritis outcome measures into Spanish. Arthritis Rheum. 1995, 38, 1429-1446. [CrossRef]

46. van Gestel, A.M.; Prevoo, M.L.; van Hof, M.A.; van Rijswijk, M.H.; van de Putte, L.B.; van Riel, P.L. Development and validation of the European League Against Rheumatism response criteria for rheumatoid arthritis. Comparison with the preliminary American College of Rheumatology and the World Health Organization/International League Against Rheumatism Criteria. Arthritis Rheum. 1996, 39, 34-40.

47. Boyum, A. Isolation of mononuclear cells and granulocytes from human blood. Isolation of monuclear cells by one centrifugation, and of granulocytes by combining centrifugation and sedimentation at $1 \mathrm{~g}$. Scand J. Clin. Lab. Invest. 1968, 97, 77-89.

48. Roederer, M. Compensation in flow cytometry. Curr. Protoc. Cytom. 2002. [CrossRef]

49. Roederer, M.; Darzynkiewicz, Z. Parks DR Guidelines for the presentation of flow cytometric data. Methods Cell. Biol. 2004, 75, 241-256.

50. Firestein GS Immunologic mechanisms in the pathogenesis of rheumatoid arthritis. J. Clin. Rheumatol. 2005, 11, S39-S44. [CrossRef]

51. Skapenko, A.; Lipsky, P.E.; Schulze-Koops, H. T cell activation as starter and motor of rheumatic inflammation. Curr. Top. Microbiol. Immunol. 2006, 305, 195-211.

52. Appay, V.; van Lier, R.A.; Sallusto, F.; Roederer, M. Phenotype and function of human T lymphocyte subsets: Consensus and issues. Cytom. A 2008, 73, 975-983. [CrossRef]

53. Okada, R.; Kondo, T.; Matsuki, F.; Takata, H. Takiguchi M Phenotypic classification of human CD4+ T cell subsets and their differentiation. Int. Immunol. 2008, 20, 1189-1199. [CrossRef]

54. Sallusto, F.; Lenig, D.; Forster, R.; Lipp, M.; Lanzavecchia, A. Two subsets of memory T lymphocytes with distinct homing potentials and effector functions. Nature 1999, 401, 708-712. [CrossRef]

55. Baeten, D.; Houbiers, J.; Kruithof, E. Synovial inflammation does not change in the absence of effective treatment: Implications for the use of synovial histopathology as biomarker in early phase clinical trials in rheumatoid arthritis. Ann. Rheum. Dis. 2006, 65, 990-997. [CrossRef]

56. Zhou, H.; Hu, B.; Zhaopeng, Z. Elevated circulating T cell subsets and cytokines expression in patients with rheumatoid arthritis. Clin. Rheumatol. 2019, 38, 1831-1839. [CrossRef]

57. Weng, N.P.; Akbar, A.N.; Goronzy, J. CD28(-) T cells: Their role in the age-associated decline of immune function. Trends Immunol. 2009, 30, 306-312. [CrossRef]

58. Effros, R.B.; Dagarag, M. Valenzuela HF In vitro senescence of immune cells. Exp. Gerontol. 2003, 38, 1243-1249. [CrossRef]

59. Goronzy, J.J. Weyand CM Rheumatoid arthritis. Immunol. Rev. 2005, 204, 55-73. [CrossRef]

60. Goronzy, J.J.; Henel, G.; Sawai, H. Costimulatory pathways in rheumatoid synovitis and T-cell senescence. Ann. N. Y. Acad. Sci. 2005, 1062, 182-194. [CrossRef]

61. Bomberger, C.; Singh-Jairam, M.; Rodey, G. Lymphoid reconstitution after autologous PBSC transplantation with FACS-sorted CD34+ hematopoietic progenitors. Blood 1998, 91, 2588-2600.

62. Gorski, J.; Yassai, M.; Zhu, X. Circulating T cell repertoire complexity in normal individuals and bone marrow recipients analyzed by CDR3 size spectratyping. Correlation with immune status. J. Immunol. 1994, 152, 5109-5119.

63. Kluin-Nelemans, H.C.; Kester, M.G. Correction of abnormal T-cell receptor repertoire during interferon-alpha therapy in patients with hairy cell leukemia. Blood 1998, 91, 4224-4231.

64. Liu, X.; Chesnokova, V.; Forman, S.J. Diamond DJ Molecular analysis of T-cell receptor repertoire in bone marrow transplant recipients: Evidence for oligoclonal T-cell expansion in graft-versus-host disease lesions. Blood 1996, 87, 3032-3044. 
65. de, V.N.; Prinsen, C.F.; Mensink, E.B.; van Riel, P.L.; van Hof, M.A.; van de Putte, L.B.A. T cell receptor beta chain variable region polymorphism associated with radiographic progression in rheumatoid arthritis. Ann. Rheum. Dis. 1993, 52, 327-331.

66. Wilson, K.B.; Quayle, A.J.; Suleyman, S. Heterogeneity of the TCR repertoire in synovial fluid T lymphocytes responding to BCG in a patient with early rheumatoid arthritis. Scand. J. Immunol. 1993, 38, $102-112$. [CrossRef]

67. Vandevyver, C.; Gu, X.X.; Geusens, P. HLA class II and T-cell receptor beta chain polymorphisms in Belgian patients with rheumatoid arthritis: No evidence for disease association with the TCRBC2, TCRBV8 and TCRBV11 polymorphisms. Ann. Rheum. Dis. 1994, 53, 580-586. [CrossRef]

68. Chara, L.; Sanchez-Atrio, A.; Perez, A. The number of circulating monocytes as biomarkers of the clinical response to methotrexate in untreated patients with rheumatoid arthritis. J. Transl. Med. 2015, 13, 2. [CrossRef]

69. Chara, L.; Sanchez-Atrio, A.; Perez, A. Monocyte populations as markers of response to adalimumab plus MTX in rheumatoid arthritis. Arthritis Res. 2012, 14, R175. [CrossRef]

(C) 2019 by the authors. Licensee MDPI, Basel, Switzerland. This article is an open access article distributed under the terms and conditions of the Creative Commons Attribution (CC BY) license (http://creativecommons.org/licenses/by/4.0/). 